\title{
Use of GIS and Orthophotos In Spatio-Temporal Assessment of Land Uses And City Expansion: A Case of Pietermaritzburg, Kwazulu- Natal, South Africa
}

\author{
Johane P. Hlatywayo ${ }^{1}$, Thomas Masvosve ${ }^{2}$ \\ ${ }^{1}$ School of Education and Sciences, Sol Plaatje University, Kimberley, South Africa, \\ johane.hlatywayo@spu.za \\ ${ }^{2}$ School of Education and Sciences, Sol Plaatje University, Kimberley, South Africa
}

DOI: http://dx.doi.org/10.4314/sajg.v4i4.11

\begin{abstract}
Land use and land cover (LULC) is important in understanding the interactions of human activities with the environment. In order to manage the often highly dynamic urban landscapes, it is important to map different themes from time to time. This study made use of Geographical Information System and aerial photographs to determine LULC transformation in the eastern suburbs of Pietermaritzburg in KwaZulu-Natal, South Africa. Land use and land cover maps for the eastern suburbs (Copesville, Eastwood, Raisethorpe and Willowton) for the years 1989 to 2009 were generated based on the twelve LULCs. Results in this study showed that the most significant increase were in residential (formal and informal) and industrial LULCs while the most significant decrease were recorded in the cultivated and open LULC. Generally, results in this study further show that urban LULC attributed to human influx has been at the expense of internal open green spaces and peripheral cultivated and uncultivated lands. The study concludes that aerial photographs in concert with GIS are valuable tools in mapping rapidly changing urban landscapes.
\end{abstract}

\section{Introduction}

Prediction of urban growth is often based on the dynamic land use/cover (LULC) pattern Vis-a- Vis selected socio-economic and environmental factors. Typically, land use change in urban landscapes is a reflection of population growth and socio-economic development. Consequently, the analysis of spatial-temporal patterns for LULC provides an objective basis for understanding the relationships between urban growth and related economic, population and environmental factors (Irwin and Geoghegan, 2001). Unsustainable urbanisation often resulted in poor environmental conditions posing pressure on the existing infrastructure and the surrounding environments (Institute for Sustainable 
Communities, 2013). A lot of scholars agree that the highest rate of urbanisation will take place in most developing countries (Seto et al., 2011). The majority of the scholars are in agreement that one third of the population will live in urban areas in Africa and it is projected that this figure is expected to rise by over 300 million between 2000 and 2030 (Cohen, 2006; UNFPA, 2007; Seto et al. 2011). The United Nation, (2011) projected a 1.2\% rate of urbanisation to take place in African continent annually. The growth of this magnitude will put pressure on the surrounding environments, especially the farms and open lands found on proximity of major cities and towns. Lebone, (2011) found that two thirds of the population in South Africa live in urban areas. Lebone, (2011) further attested that the percentage of people living in urban areas in South Africa increased from 52\% in 1990 to $62 \%$ in 2011. In the same vein, Ndebele, (2011) found that Rustenburg, Vanderbijlpark, Polokwane, Nelspruit and Ekurhuleni are the five fastest growing urban areas in South Africa with an annual average population rate of between $1.6 \%$ and $2.9 \%$ over the last ten years.

After 1991, there has been an extremely high increase of black and coloured population in most South African cities. This was due to relaxation of apartheid laws which controlled the influx of black population in urban areas.

According to (Opeyemi, 2008), land use affects land cover and changes in land cover affects land use. Generally, a change in either does not necessarily mean degradation (Opeyemi, 2008). However, Riebsame et al., (1994) note that generation of reliable LULC maps is critical in managing urban landscape as shifting land use patterns are commonly driven by a variety of social causes result in land cover changes that affects biodiversity, water and many environmental variables.

Pietermaritzburg city is no exception to the development that happened in most urban areas in South Africa after 1994. In the old political dispensation, the city of Pietermaritzburg, like any other city in South Africa was structured on apartheid racial segregation and restricted movement into urban areas. However after the end of the previous political dispensation in 1994 and the new regime that allowed free movement into urban areas, the city witnessed unprecedented growth of settlement (Wood, 2000). The majority of population settled into informal settlements near townships (Geyer et al., 2012). This phenomenon is seen in most South African cities and this has posed concern to the government, researchers and town planners. An audit done in February 1997 by the city's planning unit for instance showed that informal settlements within the city grew by a 7\% monthly average in the early years of South Africa's democratisation (Wood, 2000). Unmanaged urbanisation and lack of institutional 
framework for intersectional co-ordination in cities leads to service delivery problems, urban decay, health related issues, landscape fragmentation, encroachment into productive agricultural land, and unexpected urban spatial change (Atikinson and Marais, 2006). This subsequently results in new demands for services in urban areas in instances where the infrastructure is not developed and optimized to support the increased population. Understanding the dynamics of urban growth is therefore significant in urban land use planning (Soffianian et al., 2010). According to Ramesh (1989), these concerns have increased the relevance of LULC maps and data formats that can be used to generate such LULCs. Consequently, the city of Pietermaritzburg offers an ideal setting to test the feasibility of multi-temporal aerial photographs in LULC mapping. This therefore calls for an investigation on the consequences of the expansion of the city.

The main objective of the research is to spatially analyse the expansion of the eastern suburbs of the city of Pietermaritzburg in KwaZulu-Natal Province in South Africa and identify the factors of development of the city using GIS and aerial photographs. The aim of the study is to demonstrate the potential use of GIS and aerial photographs as tools to identify and spatially analyze land use patterns and land cover changes within a city.

Traditionally, combinations of cartographic techniques, GIS, remote Sensing and aerial photographs have been extensively used to assess LULC changes in urban landscapes (Ghaffar, 2005; Wentz et al., 2006; Hara et al., 2005). On the other hand aerial photographs have previously been used as ancillary data to validate the accuracy of land cover maps generated from remotely sensed satellite imagery (Mas, 2003; Rembold et al., 2000; Wentz et al., 2006; Deguchi and Sugio, 1994). Deguchi and Sugio (1994). Wentz et al., (2006) note that aerial photographs alone can be used to generate reliable LULC maps in urban environments.

As has been previously mentioned, previous studies seem to be focused more on the use of Remote Sensing and GIS. However, due to their relative low cost, widespread availability and high spatial resolution, multi-temporal aerial photographs have great potential in mapping urban landscapes often characterised by a complex mosaic of LULC types (Ramesh, 1989). Aerial photographs are particularly useful in determining historical LULC changes as they pre-date other LULC data sources like satellite imagery (Ramesh 1989; Rembold, 2000). In third world countries, aerial photographs can be an ideal 
data source for generating LULC maps as the availability and cost of satellite data are often prohibitive (Ramesh, 1989).

A number of studies have used aerial photographs in landscape delineation. Due to shortage of relevant satellite imagery of the study area, often common in developing countries, Reimbold et al., (2000) used aerial photographs and field survey to determine LULC in Ziwat-shala lake basin in Eithiopia. Wentz et al., (2006) on the other hand compared methods used to map LULC in an arid urban environment of Phoenix metropolitan area in USA using aerial photography interpretation (API), satellite imagery and on the ground observations (OTG) (Wentz et al., 2006). They concluded that the quality of classes based on API match those obtained from the other two methods. They further noted that differences in levels of accuracy using the three methods arise from positional errors, incorrect ground observations, or discrepancies between the sizes of sampling unit in the ground versus classes generated.

Hara et al., (2005) used aerial photographs to determine transformation on the urban fringe of Bangkok, Thailand, while Deguchi and Sugio (1994) cited by Wentz et al., (2006) compared aerial photography and a variety of satellite datasets for impervious areas and the density of urbanized area of Wake County in the state of North Carolina, USA. The two studies concluded that both aerial photography and satellite data returned results of similar accuracy. Ventura and Harris (1994) compared the performance of standard classification techniques using manual interpretation for both aerial photography and satellite data for Beaverdam, Wisconsim, USA and concluded that aerial photographs provide the higher classification accuracy in a number of LULC categories.

Robbins (1997) investigated temporal change in sea grass in Tampa Bay on Gulf coast of Florida, USA. The verification of polygon categories used in this study was conducted by sampling and ground truthing LULC types. The maps were geo-referenced and overlaid on a base map of the Tampa Bay shoreline. Comparison of total sea grass cover was made between dates by constructing a difference map using ARC/INFO GIS software.

Whereas some of the examples given above may not have been specifically carried out in urban areas, approaches and techniques used in these studies are commonly adopted and applied in urban LULC analysis. 
Until recently, the collection and compilation of spatial data was restricted to hard copy maps. As aforementioned, techniques based on hard copy maps is costly and time-consuming. The use of aerial photos in concert with GIS has made it easier to undertake LULC mapping. Large sets of data can be processed into digital forms to provide rapid and consistent measurement of change and trends. Integration of aerial photographs into GIS to monitor and analyse LULC has proved a popular and efficient method in urban landscapes (Iwao, 1998; Read et al., 2002; Saipothog et al., 2000). This has mainly been possible because GIS provides an array of spatial tools and techniques that can be used to continuously monitor and analyse LULC trends quickly, accurately and cost effectively.

\section{The study area}

The city of Pietermaritzburg is bounded between the latitudes $29^{\circ} 30^{\prime}$ to $29^{\circ} 45^{\prime}$ south and longitudes $30^{\circ} 15^{\prime}$ to $30^{\circ} 30^{\prime}$ east. The study area, which is 2375 hectares in extent, is found in the eastern suburbs of Pietermaritzburg city in KwaZulu-Natal Province. The land use changes at distinct points of 1989, 1998, 2004 and 2009 were analysed. The topographical maps created in 1982, 1989, 2000 and the zoning scheme of Pietermaritzburg (showing all the suburbs boundaries) were used as control checks, accuracy assessment and ground trothing data sets for the study area. The dates used were primarily based on the availability of aerial photographs obtained on the study area. The year 2004 was selected because it was proximity to the year when Pietermaritzburg was declared the administration capital city of the province in year 2000. The political dispensation in 2000 declared Pietermaritzburg the administration capital city when the African National Congress (ANC) came to power in the province in 2004. The capital status was removed from Ulundi and due to this newly acquired status; one would expect great changes in land use and service delivery in this city. The city experienced rapid economic growth and land prices rose sharply (uMgungundlovu District Municipality IDP, 2010; and IDP, 2003). From these years (1989 to 2009) significant changes and development were expected to happen in the study area.

The study area is found at the eastern side of the Central Business District (CBD) of Pietermaritzburg city and the National Freeway (N3) from Johannesburg to Durban. The study area is made up of four suburbs, namely Copesville, Raisethorpe, Willowton and Eastwood. Copesville and Eastwood, which are bordering farming areas, were included to investigate how much farming 
land was lost to the expanding city. Raisethope suburb is partly surrounded by other suburbs and is relatively an old suburb to other suburbs in the study area. It was included in the study to find out whether there is any land use or cover changes in old suburb areas. Willowton is an industrial area. It was included in the study so as to investigate the growth of industries in the study area. The geographic location of the suburbs of Pietermartzburg is shown in Figure 1.

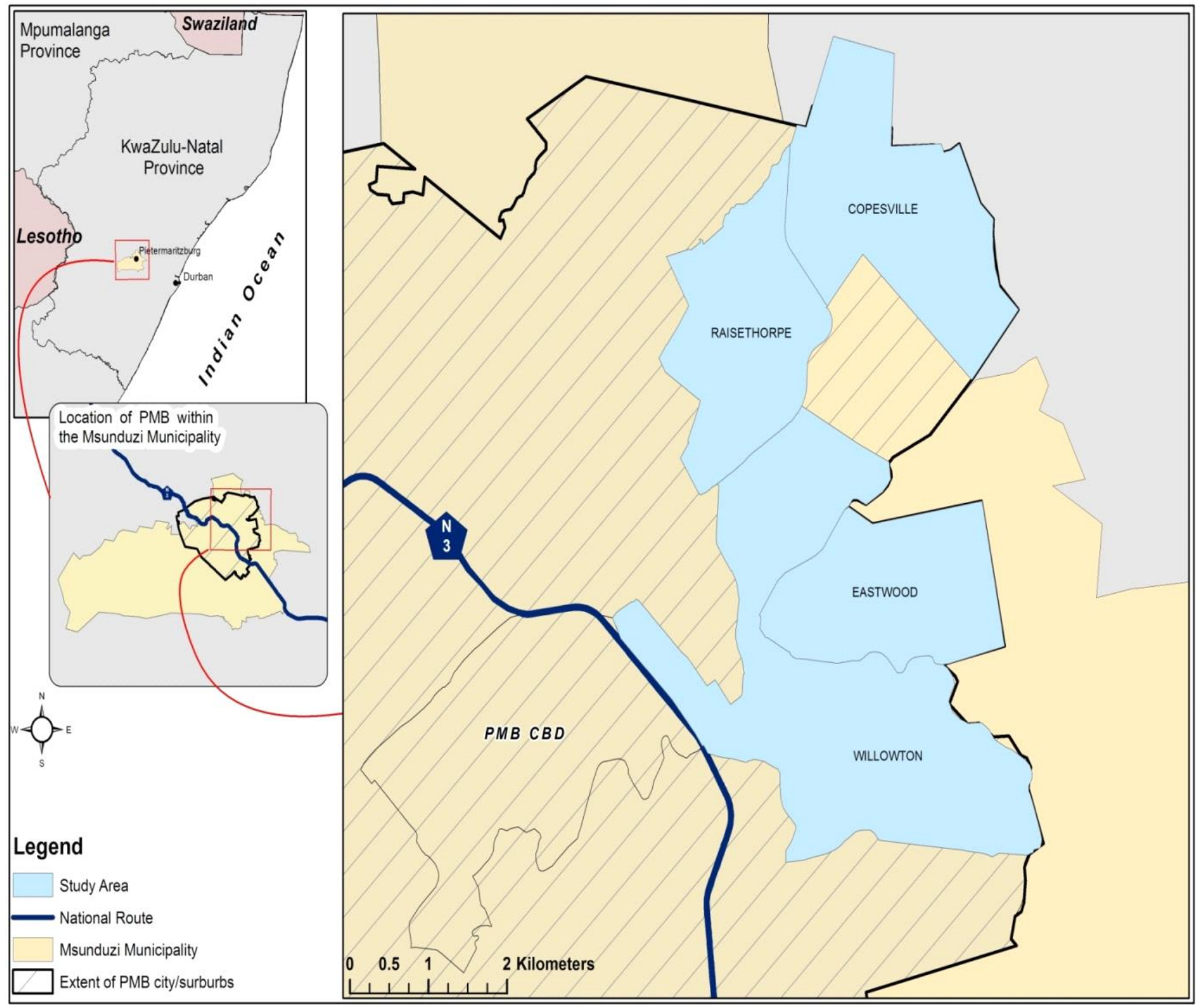

Figure 1. The location of the study area, showing urban area of Pietermaritzburg 


\section{Material and Methods}

In this study GIS and aerial photographs were used to analyse LULC change patterns in the study area. To achieve this, digital aerial photographs taken between 1989 and 2009, topographic maps produced in 1971, 1980, 1982, 2000 and the Zoning map obtained from the Department of Town Planning in the GIS department, in Pietermaritzburg city were used. A methodology illustrated in Figure 2 provides a summary of how the aforementioned objectives of the study were achieved. 


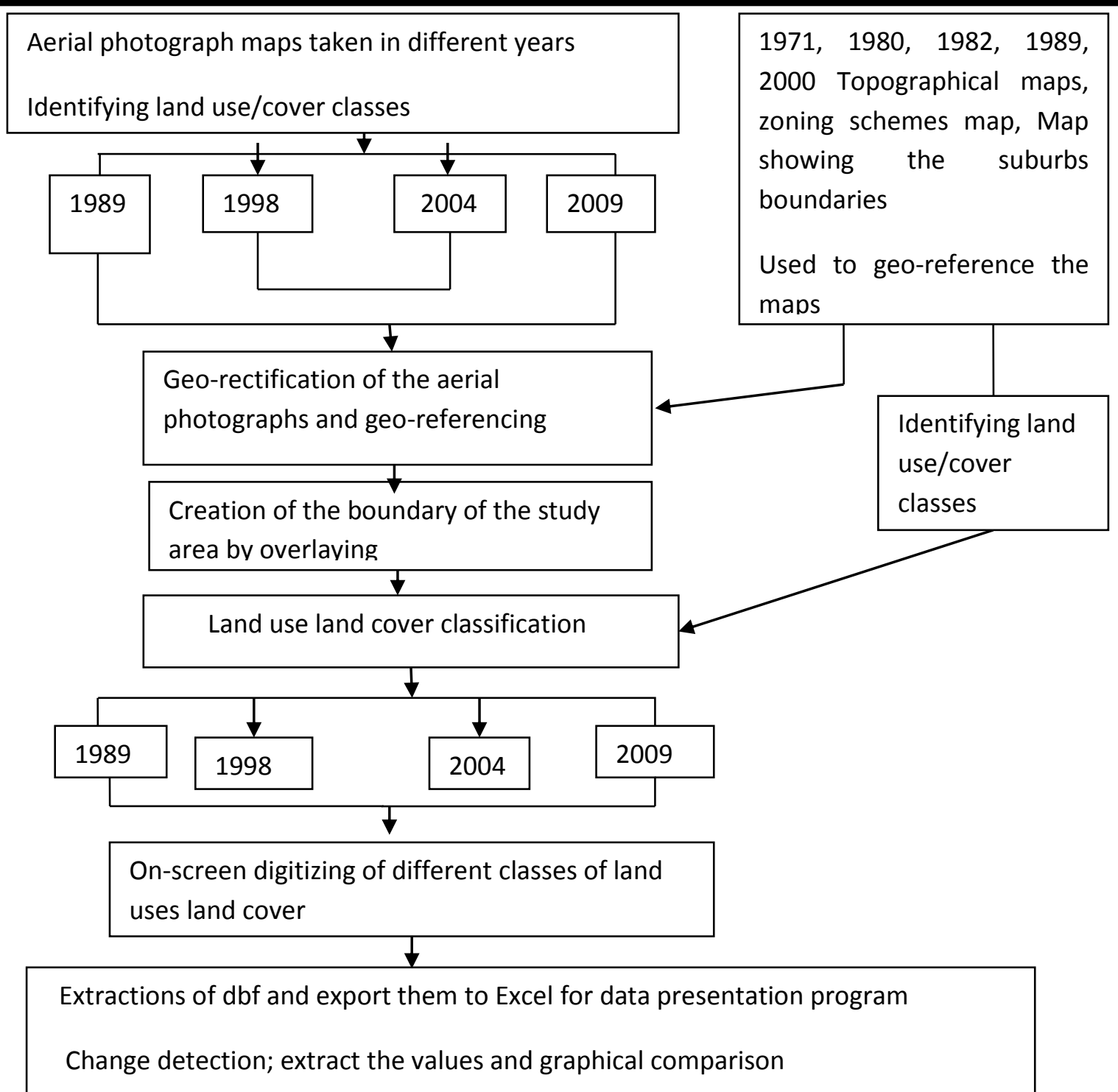

Figure 2. Procedure for mapping LULC in the study area (1989 to 2009).

\subsection{Data Processing}

The processing of data used in this research consisted of two important procedures: Georectification of the aerial photographs and On-screen digitization of the LULC classes. Georectification was done to eliminate positional errors that could affect change detection accuracy, while digitization was used to create various land use maps required for analysis. The Spline geo-rectification technique was used to geo-rectify the aerial photographs taken in 1989 and 1998. Since the 2004 and 
2009 photographs were acquired when already georectified, the 2009 photograph was used for the georectification process to accommodate any new features in existence. The geo-rectification procedures determine the accuracy of the final LULC analysis whose accuracy is dependent on the positional accuracy of individual pixels on the aerial photographs used. According to Boone et al (2007), a good positional accuracy of individual pixels that make up the entire aerial photograph implies that on any two multi-temporal photographs, pixels of a feature in the image from an earlier date correspond specifically to the location of pixels of the same feature in the image taken in a subsequent date. Accuracy assessment on 1989 imagery was done using the 1982 topographical map, 1998 and 2004 imagery accuracy assessment were carried using the 2000 topographical map, and 2009 imagery accuracy assessment was done using field observation

In this study an 'on screen' digitising was employed. After the classification of the different LULCs, different LULCs in the study area were digitised. The corrected digital orthophotos of the study area were imported and displayed in ArcCatalog making it possible to zoom in to identify locations of the boundaries between LULC types. These boundaries were digitised directly on the screen in ArcMap at an area threshold determined by the resolution of the aerial imagery.

\subsection{Land use land cover classification}

Since there are different kinds of land cover types and possible land uses, it is necessary to identify and classify land according to characteristics and use potential (Rhind, 1993). Land use and land cover maps typically enumerate the types of land usages and vegetation covering the earth. Classification as defined by FAO (2005:209) "is an abstract representation of the situation in the field using welldefined diagnostic criteria". It is a means of organising spatial information in an orderly and logical way and it's fundamental to any mapping project as it creates order in the total number of classes (Congalton and Green 1999). In order to determine the number of LULC mapping classes on a multitemporal data set, standardised classification schemes need to be followed.

The classification scheme used in this study was adopted from the guidelines by Thompson et al 
(2001). In this study a 1982 and 1989 topographical maps were used as base maps to identify and classify LULC on 1989 and 1998 aerial photographs respectively. The 2000 ( $4^{\text {th }}$ edition) topographical map was used as a base map to identify and classify LULC on 2004 and 2009 aerial photograph. The interpretation was done using urban air photo feature characteristics such as shape, size, tone, pattern and association. First, the 2000 topographic map was interpreted for LULC details and the same details were transferred to 2004 and 2009 aerial photograph. Second, aerial photographs from 1998 were interpreted for the same LULC classification as those from 2009 and details transferred into the base map by the method of matching the details. Topographic map for 1982 ( $4^{\text {th }}$ edition) was used to classify LULC for 1989 and 1998 aerial photographs. Whereas topographic maps acquired in tandem with aerial photographs could have been ideal, they were not available and the closest possible data sets (1989, 1998, 2004 and 2009 had to be used instead.

\subsection{Creating land use maps}

To create chorochromatic maps and graphically illustrate temporal aerial divisions of different LULC classes between 1989 and 2009, common boundaries of the suburbs were achieved by overlaying suburbs grids obtained from the Town Planning Department in Pietermaritzburg. The grid covering the study area was extracted from the grid that covers the whole city by selection and clipping. The grid map created was overlaid on the aerial photographs taken from the aforementioned multi-temporal periods, 1989, 1998, 2004 and 2009. The different classified LULC were saved as shape files and different colours were used to give a visual variable for each land use class.

Once all the relevant data in the orthophotos had been digitised it was necessary to edit the shape files to eliminate errors. This process involved manually moving nodes at the beginning or end of arcs. These nodes either overshot or fell short of other lines. Accidentally digitized slivers were also removed. As the polygon did not contain attribute data, corresponding attribute tables were manually populated with data associated with each individual polygon. 


\subsection{Error and accuracy assessment}

The process of transcribing information from aerial photographs to a LULC map is "essentially a process of segmenting the image into mosaic of parcels, with each parcel assigned to a land use class" (Weng, 1990). This process inevitably leads to error. According to Dunn et al., (1991) there are broad ways in which this operational error can occur. Errors can occur in interpretation of photographs and omission of parcels on the ground. Errors of commission may occur when the location of boundaries between land parcels are not clear. Errors may also occur during the digitizing process. Digitizing is essentially a sampling process where a limited number of straight lines represent the true line, which is often a smooth curve (Moore, 1997). Thus a discrepancy often exists between the positions of the original line on the map and the digitized line (Dunn et al., 1991). All the above mentioned errors were considered in the final evaluation of the generated LULC maps.

On the ground observation (OTG) (Wentz et al, 2006) was employed in this study to verify sites and LULCs. Ten sets of co-ordinates in each classified land use were chosen for accuracy assessment. These points were then located in the field using GPS instrument, first by locating these points on the aerial photographs. The LULC types and objects which corresponded to these co-ordinates on 1998, 2004 and 2009 LULC map were identified. The same positions were then located in the field using a Global Positioning System (GPS). The OTG exercise produced eight sites out of ten which were correct in each land use classified and two sites were slightly incorrect.

\section{Results and discussion}

\subsection{General LULC changes in the study area}

The land uses for 1989 to 2009 are given in Figure 3 and Table 1. The LULC datasets produced from the aerial photographs data show spatial location, distribution and surface area of the LULC classes in the four suburbs studied (Copesville, Raisethorpe, Eastwood and Wilowton). Table 1 and figures $3,4 \& 5$ show the changes that took place in the study area. 
South African Journal of Geomatics, Vol. 4, No. 4, November 2015

Table 1: Areas (hectares) for 1989 to 2009 LULC.

\begin{tabular}{|l|r|r|r|r|}
\hline & 1989 & 1998 & 2004 & 2009 \\
\hline Land use/land cover type & Area (ha) & Area (ha) & Area (ha) & Area (ha) \\
\hline Business & 10 & 18.5 & 20 & 21 \\
\hline Cultivated land & 571.5 & 180 & 66.8 & 11.01 \\
\hline Education & 16.9 & 26.8 & 33.52 & 38.1 \\
\hline Hospital & 0 & 0 & 2.95 & 2.95 \\
\hline Industries & 219.5 & 312 & 317.6 & 374.26 \\
\hline Formal residential area & 380 & 448 & 623.2 & 656.47 \\
\hline Informal residential area & 26 & 174 & 210 & 264.97 \\
\hline Municipal & 100.5 & 140 & 140.1 & 140.1 \\
\hline Recreation & 32 & 180 & 44.1 & 57.08 \\
\hline Trees and bushes & 756.1 & 572 & 627.2 & 583.65 \\
\hline Planned undeveloped residential area & 25.1 & 85.4 & 69.4 & 5.68 \\
\hline Water reservoir & 0 & 1.1 & 1.1 & 1.1 \\
\hline
\end{tabular}



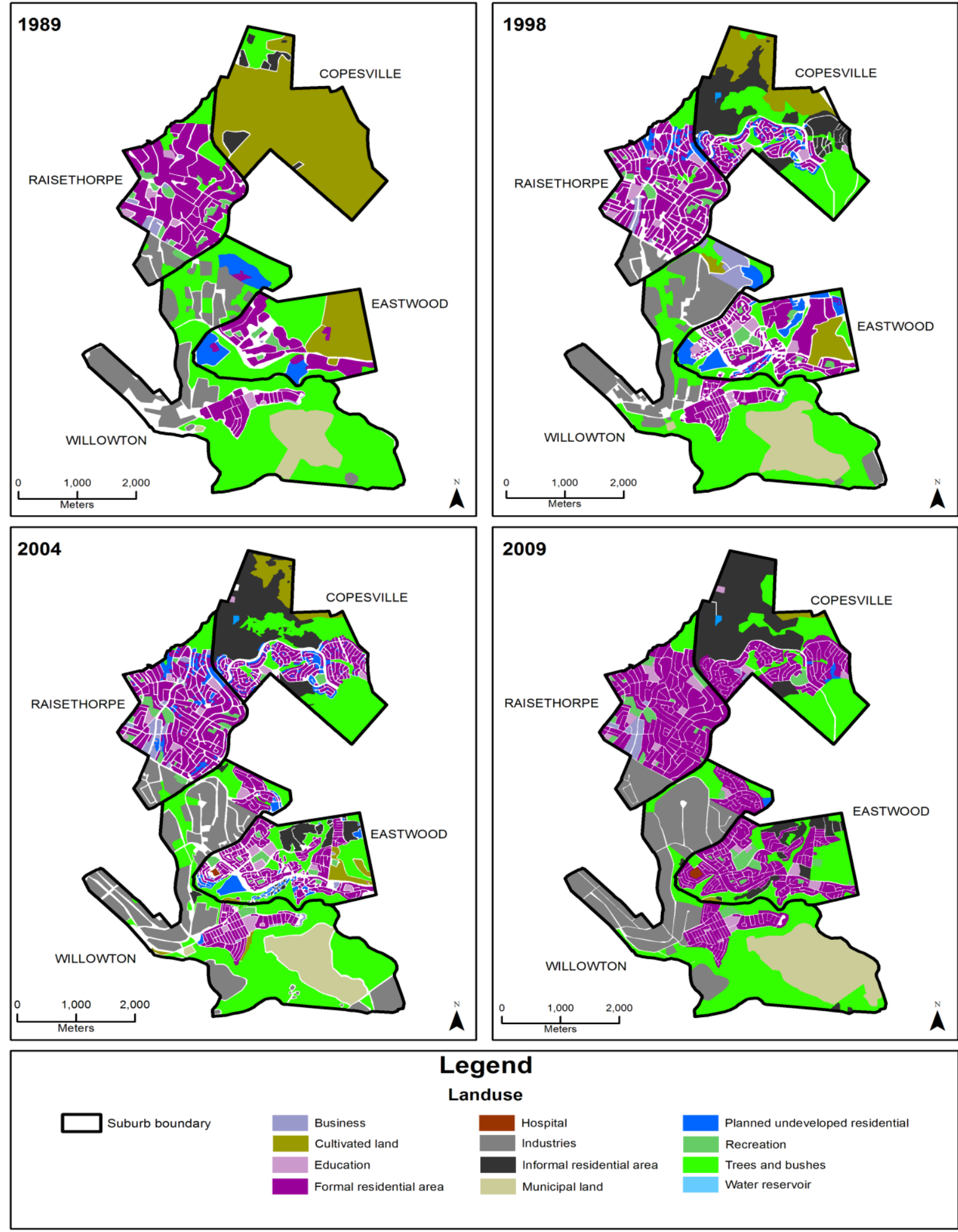

Figure 3. Digitized LULC maps of the study area (1989 to 2009). 
Table 2 and Figure $3 \& 4$ show changes in hectares in the study area. Cultivated LULC class decreased from 571.5 hectares in 1989 to 11.01 hectares in 2009 while residential areas doubled from 406 hectares in 1989 (formal and informal combined) to 921.144 hectares in 2009. Industrial and education LULC steadily increased over the study period Table 1.

\subsection{Percentage changes between 1989 and 1998 (9year period)}

The 1998 maps (Figure 5) show that formal residential area increased from17.8\% in 1989 to $20.96 \%$ in 1998 (3.16\%). Cultivated land decreased from $26.7 \%$ in 1989 to $8.4 \%$ in 1998, a decrease of $18.3 \%$. Industries increased by $4.3 \%$ over this period. Informal residential and planned undeveloped residential LULC increased by $7.2 \%$ and $2.79 \%$ respectively (figure 4)._Cultivation was the most dominant LULC in Copesville with $89.8 \%$ of the total area under cultivation in 1989. In this area, only $5 \%$ of the land was used for informal residential while $27.6 \%$ of the land was covered by trees and bushes. In Eastwood, the main LULC was trees and bushes (149.3 hectare of the total area of 361.8) which translated to $41.3 \%$. This was followed by cultivated LULC (27.5\%) and formal residential (27.7\%). In Raisethorpe, the major LULC was formal residential which constituted $65.5 \%$ of the total area, followed by trees and bushes which constituted about $13.6 \%$ of the total area. In Willowton the main LULC was trees and bushes which constitute about $59.2 \%$ of the total area of the suburb followed by industrial (20.6\%) and municipal land (11.2\%).

The results obtained from 1998 from the entire study area shows that the formal residential area increased from $0 \%$ in 1989 to $10.9 \%$. Land under cultivation decreased by $64.5 \%$. In Eastwood the main LULC was formal residential area (43.8\%), trees and bushes (19.2), undeveloped planned residential area (13.6) and cultivated land (13.4). In Willowton trees and bushes increased by about 1.6\% from 1995. (13.4). In Eastwood, undeveloped planned residential stands increased from 5.4\% to 13.6\%. Cultivated land also decreased from $31.6 \%$ to $13.4 \%$. This means that most of the land used for farming was lost to residential or built up areas.

The Copesville results obtained in 2004 show that the informal residential class increased by $3.3 \%$ and the undeveloped residential class decreased by $1.1 \%$ from the previous data set (1998). In 
Eastwood, the formal residential class increased by $17.8 \%$ and undeveloped planned residential plots dropped by $4.8 \%$. This means that a lot of undeveloped planned plots were developed into formal residential areas. Furthermore, formal residential class increased in Raisethorpe while undeveloped planned residential areas decreased from the previous temporal dataset by $2.5 \%$ and $2.5 \%$ respectively. Results also show that the industrial LULC class in Willowton increased by $5.8 \%$ and formal residential class increased by $2.6 \%$ between 1998 and 2004.There was a significant change in cultivated LULC in 2009 in Copesville. In Copesville, this LULC class decreased from 8\% in 2004 to $1.6 \%$ in 2009 . Formal and informal residential areas increased by $3.5 \%$ and $5.2 \%$ respectively.

Table 2: Overall LULC change for 1989 to 2009 LULC.

\begin{tabular}{|l|r|r|r|r|}
\hline Land use/land cover type & Area 1989 (ha) & Area 2009 (ha) & Change(ha) & $\begin{array}{l}\text { \% } \\
\text { change }\end{array}$ \\
\hline Business & 10 & 21 & 11 & 110 \\
\hline Cultivated land & 571.5 & 11.01 & -560.49 & -98 \\
\hline Education & 16.9 & 33.52 & 16.62 & 98.3 \\
\hline Hospital & 0 & 2.95 & 2.95 & 100 \\
\hline Industry & 219.5 & 374.26 & 154.76 & 70.5 \\
\hline Formal Residential area & 380 & 644.7 & 264.70 & 69.7 \\
\hline Informal residential area & 26 & 264.97 & 238.97 & 919.1 \\
\hline Municipal & 100.5 & 140.1 & 39.6 & 39.4 \\
\hline Recreation & 32 & 57.08 & 25.08 & 78.4 \\
\hline Trees \& bushes & 756.1 & 583.65 & -162.35 & -21.4 \\
\hline Planned undeveloped residential area & 25.1 & 5.68 & -19.32 & 77 \\
\hline Water & 0 & 1.1 & 1.1 & 100 \\
\hline
\end{tabular}




\subsection{Changes between 1989 and 2009 ( 20 years period)}

Cultivated land, trees and bushes and planned undeveloped residential classes saw a negative growth over the study period (Table 2). Over 560 hectares of land under cultivation and 162.35 hectares of land under trees and bushes were lost over the study period of 20 years (Figure 4 and Table 2) Land which was lost from the aforementioned classes was gained by other classes which experienced some increase over the study period. Formal and informal residential area classes show a net gain of over 419 hectares. Formal residential area increased by $69.7 \%$ and informal residential area increased by $919 \%$ over 20 years. (Table 2$)$

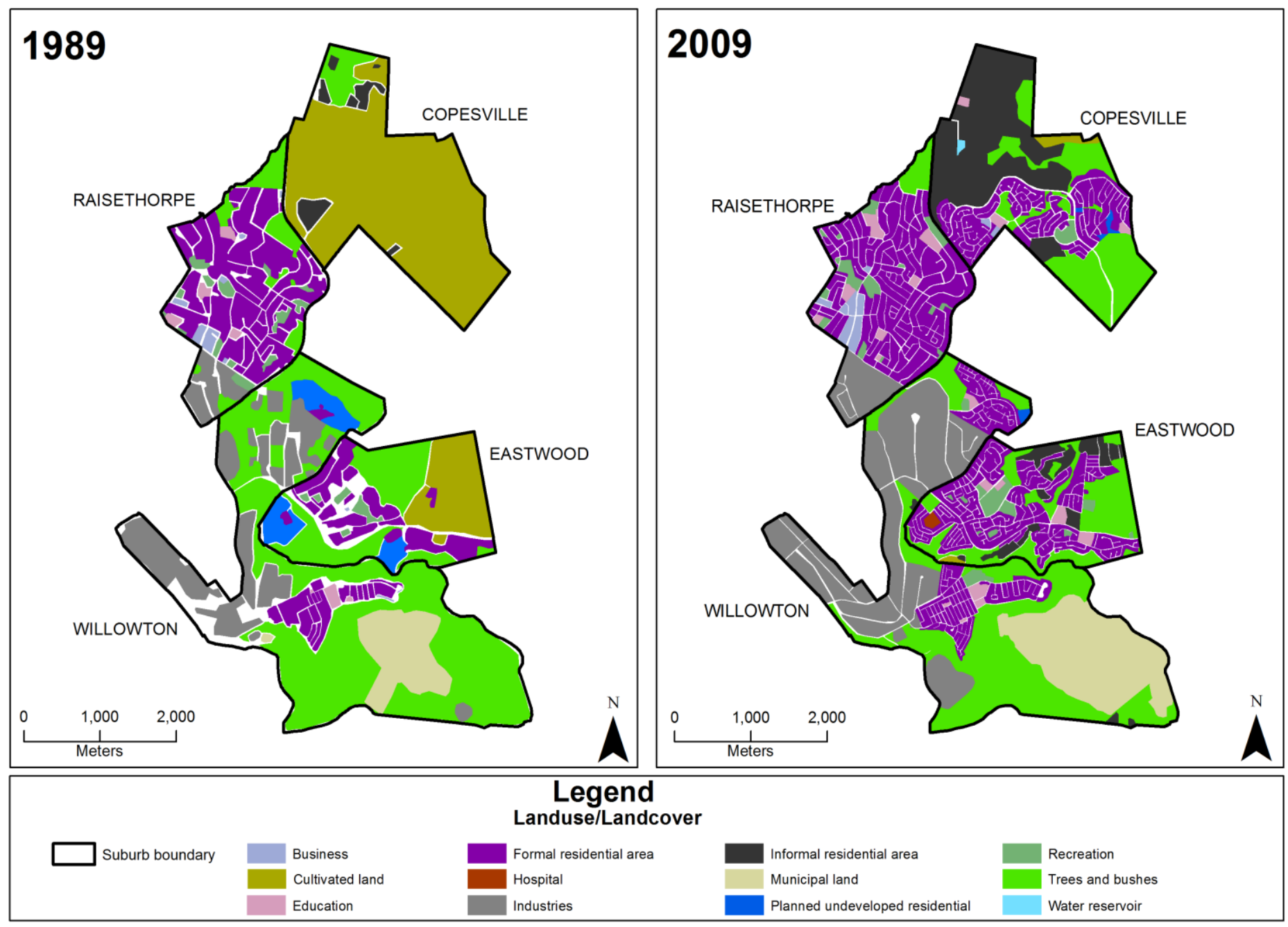

Figure 4 Land use cover change map 1989 to 2009 (20 year period) 

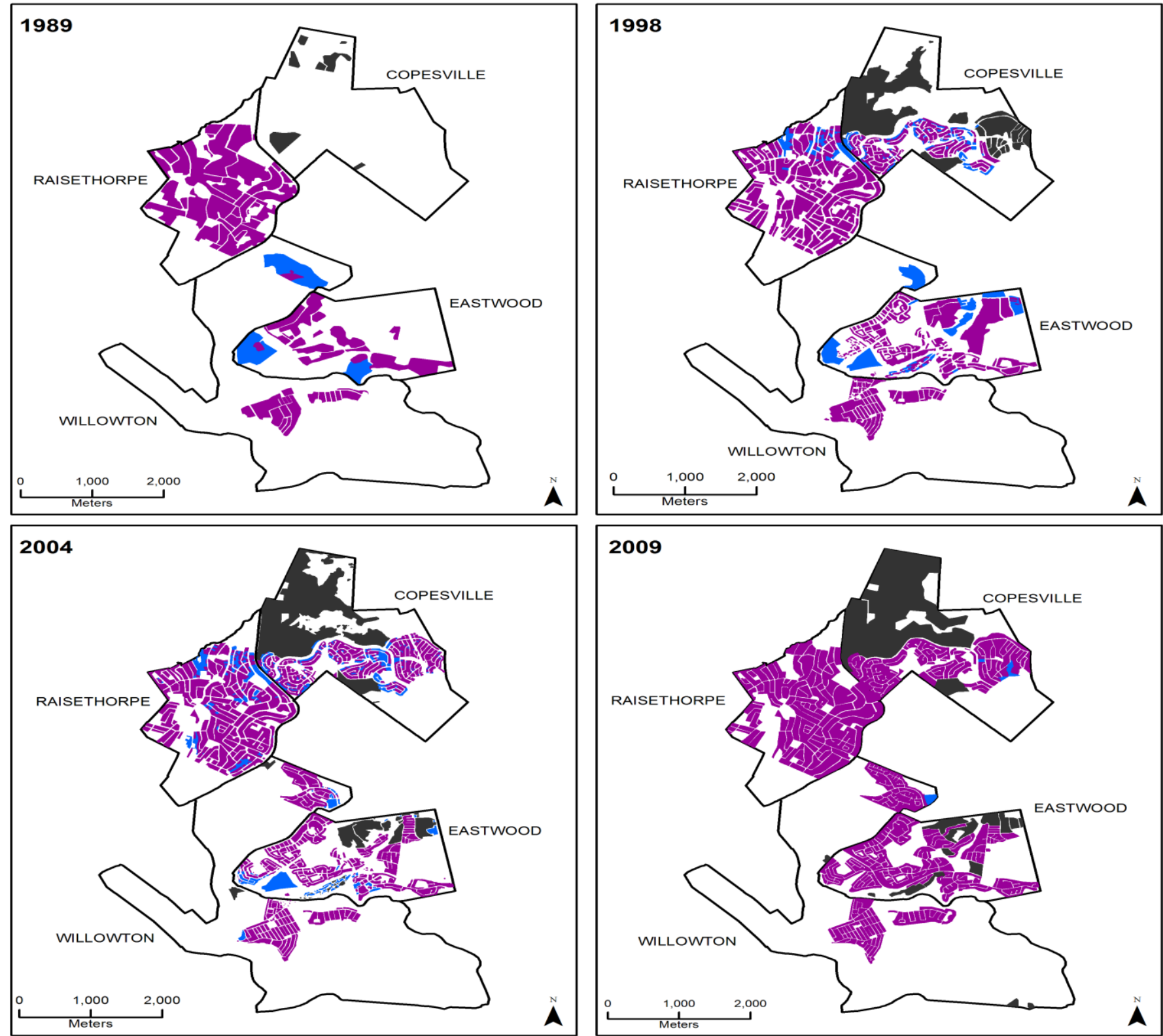

Legend

Landuse

Formal residential area

Planned undeveloped residential

Informal residential area

Figure 5. The extent of the formal, informal and planned undeveloped residential areas from 1989 to 2009. 
Figure 5 shows the spatial extents of major LULC types that had the most significant changes followed by a breakdown of suburb by suburb.

\subsection{Possible causes of urban growth in the study area}

This section is going to discuss possible reasons which saw the change of land use in the study area

\subsubsection{Economic theory}

The expansion of the study area over the years was a result of a number of factors. Pietermaritzburg city, which falls under Msunduzi municipality, is surrounded by six municipalities. These municipalities play a critical role in "importing" goods, services and human capital to the city. As a result the city is bound to expand both in space and services. Based on spatial trends already discussed, it can be concluded that the city has expanded due to economic factors which further attracts people into the area of study. The transformation of LULC in the study area can be explained by the economic base theory. The theory hypothesise that the size of an urban area depends on the amount of goods and services that is supplied to "outsiders". The income derived from "out-supply" generate purchasing power which sustains internal demand. The increased internal demand driven by higher purchasing power will increase population inflow to the urban centre (Harvey, 1996).

This might be true as more and more people migrate to urban areas, in this case into Pietermaritzburg, more goods and services will be consumed and the income generated from these activities are used to expand the business in the study area and attracts more people.

\subsubsection{Laws, politics and the past history}

The pass law during the apartheid regime made it illegal for black people to live in white areas. Black people were not allowed to rent formal houses and were restricted to informal dwellings. When these restrictions and other racial restrictions were lifted up in 1994, as in the case of many other urban 
settlements in South Africa, there was unprecedented rural urban migration (Cronje, 2009). The shifting of provincial capital status from Ulundi to Pietermaritzburg in 2004 triggered the cities' urban expansion. This had a spiral demand on residential and associated services. It can be assumed that there was an influx of people who wanted to exploit opportunities offered by the city's new status.

\section{Conclusion}

The main objective of this research was to establish spatio-temporal change patterns that took place in the study area using GIS and aerial photograph maps. It went on to investigate the capability of GIS in effectively analysing LULC and, LULC trends using maps generated from aerial photograph. It was assumed from the outset that the spatial approach using aerial photographs and GIS would provide better insight and understanding of the LULC dynamics in the eastern suburbs of Pietermaritzburg.

The information generated in this project can assist in answering the following questions: why is LULC in its current state? Has it changed and why? How do these changes occur and what factors contributed to these changes? Furthermore the information generated has potential for use by the municipality for spatial planning and mitigation of urban sprawl. The following conclusions can be drawn from this study. During the study period (1989 to 2009), there was a significant LULC change, particularly in Copesville. The land which was mainly used for agriculture in 1989 changed into residential in subsequent years. Cultivated land decreased while formal residential and informal residential LULC increased. Planned undeveloped residential areas increased from 25.1 hectares in 1989 to 85.4 hectares in 1998 but decreased in 2004 (69.4 hectares) and 2009 (5.68hectares) (see Table 1). Industrial LULC increased from 1989 (219.5 hectares) to 1998 (312 hectares). About 42\% increase was realised over this period.

The significant increase in residential area (formal and informal) is attributed to the influx of rural-urban migration from the surrounding areas. Understanding the changes in the use and cover of land resources is critical for land management and planning. This study validates aerial photographs and GIS techniques as effective tools for mapping heterogeneous and dynamic urban landscapes. 
Such a process is valuable for assessing, monitoring and planning urban physical, social and natural resources.

\section{References}

Atikinson D, Marais L, 2006, 'Urbanisation and the Future Urban Agenda in South Africa' in Udesh Pillay, Richard Tomlinson Ed, Jacques Du Toit (eds), Democracy and Delivery: Urban Policy in South Africa, HSRC Press.

Cohen B, 2006, 'Urbanization in developing countries: Current trends, future projections, and key challenges for sustainability', Elsevier, vol. 28, pp. 63-80.

Congalton, R., G. and Green, K., 1999, Assessing the accuracy of remotely sensed data: Principles and practices, Lewis Publishers, New York.

Cronje I., Finance MEC, "Expectations of a Capital City", on the occasion of Msunduzi Innovation and Development Institute strategic summit, Three Cities Hotel Conference Centre, Golden House Complex, Pietermaritzburg, Department of Finance, KwaZulu-Natal Provincial Government 20 October 2009.

Deguchi, C. and Sugio, S., 1994, Estimation for percentage of Impervious Area by the use of satellite Remote sensing Imagery, IWA Publishing Journal, Vol.29 no.2, pp.135-144.

Dunn, C.P., Sharpe, D. M., Guntenspergen, G. R. and Yang, Z., 1991, Methods for Analyzing Temporal Changes in Landscape Pattern, in Turner, M.G.and Gardner, R. H. (eds) Quantitative Methods in Landscape Ecology, Springer,Dordrecht.

FAO, 2005, Land covers classification system-Classification concepts and user manual: Natural Resources $\begin{array}{lllll}\text { Management and Environment } & \text { Department. } & \text { [Online] }\end{array}$ at:www.fao.org/docrep/008/y7220e/y7220e00.htm (Accessed November 2011)

Ghaffar, A., 2005, 'Monitoring land use change: Use of Remote Sensing and GIS. Department of Geography, University of the Punab Lahore, Pakistan'. Geographical Review, vol.60, no.1, pp.19-26.

Geyer Jr H.S, Geyer H.S, du Plessis D.J, 2012, 'Differential urbanisation trends in South Africa-regional and local equivalents', Environment and Planning, vol. 44, pp. 2940-2956.

Hara, Y., Takeuchi, K., and Okubo, S., 2005, 'Urbanization linked with past agricultural Landuse patterns in the urban fringe of a deltaic Asian mega-city: A case studying of Bangkok, Landscience'. Urban Plann, vol.73, pp.16-28.

Harvey, D., 1996, 'Justice, Nature and Geography of Difference', American Geographical Society, vol.84, no. 4, pp.555-557.

Harvey, K. R. and Hill, G. E., 2001, 'Vegetation mapping of a tropical freshwater swamp in the Northern Territory, Australia: A comparison of aerial photography, landsat TM and SPOT satellite imagery', International Journal Remote Sensing, vol.22, no.15 pp.2911-2625

Institute for Sustainable Communities, 2013, 'Urbanization, Infrastructure and Economic Growth In Southeast Asia', http://www.iscvt.org/news/urbanization-infrastructure-and-economic-growth-in-asia/.

Irwin, E. G. and Geoghegan, J., 2001, 'Theory, data, and methods: developing spatially explicit economic models of land use change', Agriculture Ecosystems \& Environment, vol.85, no.1-3 pp.7-23.

Iwao, K., 1998: Landuse study for South Asia. [Online] Available at:http://Shiba.iis.utokyo.ac.jp/maber/current/koki/WAOE.htm/ (Accessed Novermber (2011)

Lebone K, 2011, More people living in urban areas than ever before, South African Institute of Race 
South African Journal of Geomatics, Vol. 4, No. 4, November 2015

Relations, 24January,http://www.sairr.org.za/media/media-releases/Urbanisation\%20\%2024\%20January\%202011.pdf/view

Mas, J. F., 2003, 'Monitoring land covers changes: A comparison of detection Techniques', International journal of remote sensing, vol.20, pp.139-152.

Moore, N. A., 1997, The use of geographic Information System to examine changes in land use patterns in the Midmar catchment. Unpublished dissertation, University of Natal, Pietermaritzburg.

Msunduzi IDP 2003-2010 Land Reform Programme KwaZulu-Natal District Plan: Final Report

Draft

Status QuoReport Urban and Rural Planning and Development Consultants, [Online] Available at

http://devplan.kzntl.gov.za/idp_reviewed_2008_9/IDP/kz2225/adopted/musunduzi\%20IDP\%202

Msunduzi IDP 2008-2012 Land Reform Programme KwaZulu-Natal District Plan: Final Report,[Online] Available at:http://devplan.kzntl.gov.za/idp_reviewed_2008_9/IDP/kz2225/adopted/musunduzi\%20IDP\%202

Ndebele T, 2013, 'South Africa goes with the urbanisation flow', South African Institute of Race Relations, 22 January 2013, www.sairr.org.za/media/media-releases/Urbanisation.

Opeyemi, Z. A., 2008, 'Monitoring the growth of settlements in Ilorin, Nigeria: A GIS and Remote sensing approach, The International archives of the photogrammetric', Remote sensing and spatial information sciences, vol. xxxvii, no.b6b, pp. 225-235.

Ramesh, B., 1989, 'Urban land use and change detection using sequential Aerial photographs and Spot Image case study: Chiangmai, Thailand Human settlement Analysis Group, India Institute of Remote Sensing, Dehradur', Journal of the Indian Society of Remote Sensing, vo.17, no.3, pp. 101-108.

Read, J. M. and Lam, N. S. M., 2002, Spatial methods for characterizing land cover and detecting land coverchanges for tropics. In: Edgar, E.; 2004: Monitoring land use and land cover changes in Belize, 19932003: a digital change detection approach. Published MSc. Thesis, The College of Arts and Sciences, Ohio.

Rembold, F., Carnicelli, S., Nor, M. and Ferrari, G. A., 2000, 'Use of aerial photographs Landsat TM imagery and multidisciplinary field survey for land-cover change analysis in the lakes region Ethiopia', International Journal of Applied earth observation and Geo information, vol.2, no.3-4, pp. 181-189.

Rhind, D. W., 1993, 'Policy on the supply and availability of ordinance survey information over the next five years', Mapping Awareness vol.7, no.1, pp. 37-41

Riebsame, W. E., Meyer, W. B., Turner II, B. L., 1994, Modeling land use and cover as part of global environmental change, Climatic Change, George Perkins marsh Institute, Worcester.

Robbins, B. D. 1997, 'Quantifying temporal change in sea grass area1 coverage: the use of GIS and low resolution aerial photography', Aquatic Botany, vol.58, no.3-4, pp. 259-267.

Roblin, H. S., 1969, Geographic Coordinates Systems \& Map projections. Fletcher and Sons, Norwich.

Saipothog, P., Weyer, H. and Thomas, D., 2000, Potential of GIS for local land use planning, a case study in Mae Chaem, Northern Tailand [on-line] Available at: http://www.mekonginfo.org/mrc=en/doclib.nsf/0/637B400DA096107C72/5681800323CD7 FileFullTEXT $>$ htm (Accessed November 2010).

Seto K, Fragkias M, Güneralp B, Reilly M, 2011, 'A Meta-Analysis of Global Urban Land Expansion', PlosOne, vol. 6, no 8, pp. 1-9.

Soffianian A, Ahmadi M, Nadoushan, Yaghmaei L and Falahatkar S, 2010, 'Mapping and Analyzing Urban Expansion Using Remotely Sensed Imagery in Isfahan, Iran'. World Applied Sciences Journal, vol. 9, no 10, pp. 
1370-1378.

Thompson, M. W., Van Den Berg, H. M. and Newby, T. S., 2001, Guide Procedures for National Land cover mapping and change monitoring, version 2. Terrestrial Resources and Environmental Management, CSIR and Agricultural Research Council. [Online] Available at:http//www.csir.co.za/websource/pt10002/images/environmentek/nlc2000/appendices/25558-1pdf. (Accessed June 2011).

United Nations Population Fund (UNFPA), 2007, 'Linking population, poverty and development; Urbanisation: A majority in Cities', http://www.unfpa.org/pds/urbanization.html.

Ventura, S. J. and Harris, P., 1994, 'A coparison of classification techniques and data sources for urban land use mapping', Geocarto International, vol.9, pp. 5-14.

Weng, F., 1990, 'Improving remote sensing image analysis through fuzzy information representation' Photogrammetric Engineering and Remote Sensing, vol.56 no.8, pp. 1163-1168.

Wentz, E. A., Stefanov, W., Gries, C. and Hope, D., 2006, 'Land use and land cover mapping diverse data sources for an arid urban environments: Department of Geography, Arizona University,Tempe,:Image Science and analysis Laboratory', Computers, Environment and Urban Systems, vol. 30, pp. 320-346.

Wood, L., 2000, 'Residential Real Estate Transfers in Pietermaritzburg-Msunduzi, South Africa', Journal of Economic and Social Geography, vol. 91, no.3, pp. 263-277. 